\title{
Hematological Profile of Sheep Experimentally Infested with Bovicola ovis
}

\section{Abebe Tadie ${ }^{1}$, Getachew Terefe ${ }^{1}$ and Yonas Gizaw ${ }^{2 *}$}

${ }^{1}$ College of Veterinary Medicine and Agriculture, Addis Ababa University, Ethiopia

${ }^{2}$ College of Veterinary Medicine, Jigjiga University, PO Box: 1020 Jigjiga, Ethiopia

*Corresponding author: Yonas Gizaw, College of Veterinary Medicine, Jigjiga University, PO Box: 1020 Jigjiga, Ethiopia, Tel: +251910417497; E-mail: yonasg5@gmail.com

Rec date: February 21, 2018; Acc date: April 21, 2018; Pub date: April 23, 2018

Copyright: (c) 2018 Tadie A, et al. This is an open-access article distributed under the terms of the Creative Commons Attribution License, which permits unrestricted use, distribution, and reproduction in any medium, provided the original author and source are credited.

\begin{abstract}
Changes in some haemotological parameters (erythrocyte count, hematocrit values and leukocyte counts) in animals with lice infestation had been reported previously. In this regards, information on the effect of Bovicola ovis (B. ovis) infestation on hematological values under experimental condition in Ethiopian sheep is not available. A total of 12 animals divided into two groups of six animals each were used in the experiment. Animals in one group were infested with 500 lice (Bovicola ovis) per sheep collected from different donor animals and the other group served as a non-infested control. Each group was observed for a period of eight consecutive weeks. The present findings demonstrated that the mean parasite burden $/ 10 \mathrm{~cm}^{2}$ of skin was 16 in infested group whereas the control group did not have any lice. Packed cell volume was not significantly different between the two groups and values were in the normal range. On the other hand total $R B C$ count was significantly lower for the infested group $(P<0.05)$. Comparison of the leukocyte counts between the two groups indicated that the total count and eosinophil levels were significantly elevated in the infested group $(\mathrm{P}<0.05)$. In conclusion, $B$. ovis infestation results not only skin damage but also causes systemic changes that may significantly alter the physiological and health status of infested animals.
\end{abstract}

Keywords: Bovicola ovis, Effect; Experimental group; Hematology; Infestation; Sheep

\section{Abbreviations}

AAU-CVMA: Addis Ababa University College of Veterinary Medicine and Agriculture; B. ovis: Bovicola ovis, $\mathrm{cm}^{2}$ : Centimeter square; EDTA: Ethylene Diamine Tetra Acetic Acid; P. ovis. Psorebtus ovis, PCV: Packed Cell Volume; RBC: Red Blood Cells; WBC: White Blood Cells.

\section{Introduction}

Ectoparasitism is one of the most important factors that hinder the productive efficiency of farm animals, as it causes hypersensitivity, marked blood loss, secondary infestation, excoriation and ultimately death in few cases. Also, ectoparasites cause indirect harm, particularly when present at high intensities, causing disturbance, increasing levels of behavior such as rubbing and reduced time spent for grazing or ruminating and in some cases, self-wounding [1].

Ectoparasites are ubiquitous, often highly damaging and in most cases cannot be permanently eradicated, as a result ectoparasitism represents a major obstacle to development and utilization of animal resource [2]. Among ectoparasites of veterinary importance namely lice (both sucking as well as biting types), sheep ked, ticks and mange mites were reported to be abundant and known to affect both large and small ruminants while their prevalence and distribution varying in different agro-ecological zones [3].

Lice are the major ectoparasites that harbor sheep [4]. Lice are specialized insects adapted to parasitize many warm-blooded vertebrates with generally high host specificity [5]. They are wingless, dorso-ventrally flattened, permanent ectoparasites of birds and mammals [6]. Three species of louse commonly infest sheep: the chewing louse Bovicola ovis (formerly called Damalinia ovis) and the two blood sucking lice Linognathus ovillus (the face louse) and $L$. pedalis (the foot louse) [7].

The most common lice affecting sheep are sheep body lice (Bovicola ovis) [8]. Bovicola ovis is a pale yellow insect 1.5 to $2 \mathrm{~mm}$ long with brown transverse stripes on the abdomen and a broad, red-brown head. It is a chewing louse and feeds on skin scurf, lipid and sweat gland secretions, superficial skin cells and skin bacteria [9]. The common sites of $B$. ovis infestation are the skin of neck, shoulder, sides and back [3].

Most transmission occurs when sheep make direct contact with each other, such as between ewes and lambs and when sheep are yarded, shaded or in sheep camps. The risk of spread will be increased if sheep have short wool, greater opportunity for close contact, been exposed to conditions which encourage lice to move to the wool tip, i.e., warmth and shade or been in contact with heavily infested sheep compared to light infestations. Infestation intensity decreases under extreme hot or cold temperatures, when the fleece is wet [8].

Lice infestation in Ethiopia is the most frequently reported and the most important skin disease of sheep and are found to be the cause of cockle. Bovicola ovis is a highly prevalent lice in sheep [10]. A recent study in Ethiopia by Seyoum indicated that the prevalence of Bovicola ovis is about $8.9 \%$ in Northwest Ethiopia [11].

Lice infestations have been associated with blood loss, reduced newborn birth weights [12] and behavioral changes such as excessive scratching and decreased weight gains [13]. Heavy louse infestations may cause pruritus, alopecia and self-wounding [14], anorexia and cachexia [15]. Severe infestation with sucking lice may cause anaemia, 
which may be severe enough to be the cause of death. Changes in some haemotological parameters (erythrocyte count, hematocrit values and leukocyte counts) in animals with lice were reported [16]. In this regards, research on the effect of Bovicola ovis infestation on hematological values under experimental condition in Ethiopian sheep is not available. It is expected that, in addition to the skin damage they can affect host physiology through either the damage on the skin surface or reduced feeding. Therefore, the objective of the present study was to assess the effects of Bovicola ovis on the hematological profiles of experimentally infested sheep.

\section{Materials and Methods}

\section{Study area}

The Experimental study was conducted at the College of Veterinary Medicine and Agriculture of Addis Ababa University in Bishoftu from February to May 2015. Bishoftu is located about $45 \mathrm{kms}$ south east of Addis Ababa at $9^{\circ} \mathrm{N}$ latitude and $40^{\circ} \mathrm{E}$ longitudes at an altitude of 1850 meters above sea level in central high land of Ethiopia. It has an annual rainfall of $866 \mathrm{~mm}$ of which $84 \%$ is in the long rainy season (June to September). The dry season extends from October to February. The mean annual maximum and minimum temperatures are $26^{\circ} \mathrm{C}$ and $14^{\circ} \mathrm{C}$ respectively, with mean relatively humidity of $61.3 \%$ [17].

\section{Experimental animals}

Twelve sheep aged $1 \frac{1 / 2}{2}$ year were purchased from local market of Asella and Sagure. Before transportation animals were treated with long acting oxytetracyclin (Alamycin LA, Norbrook, Ireland). On arrival at College of Veterinary Medicine and Agriculture at Bishoftu, Addis Ababa University, the animals were subjected for one month acclimatization period, during which they were ear-tagged and screened for hemoprotozoa along with internal and external parasites as well as other diseases. Animals were dewormed with albendazole (Albenda-QK, Chengdu Qiankun, China), and ivermectin (Ivermectin $1 \%$, Chengdu Qiankun, China) up on arrival. Additional treatment was also made with triclabendazole (Fasionox, East African pharmaceuticals P.L.C., Ethiopia) before starting the experiment. Prior to the study, animals were transferred to a standard animal facility built by Hide and Skin project.

\section{Experimental groups and infestation}

The experimental animals were divided into two groups each group containing six sheep. Group I was infested with Bovicola ovis and Group II was left uninfested as a control group. Animals in one group were infested with 500 lice per sheep collected from different donor animals and the other group served as a non-infected control. Each group was kept in a separate pen within the standard animal facility (Annex 1). Infestation was done by using parasites collected from naturally infested donor animals. The parasites were collected, counted and identified. Then, they were deposited at the base of the hairs on five different sites and the hairs on the sites were fixed by a scotch tape to prevent falling and facilitate dispersion along the skin surface (Annex 2).

\section{Feeding and animal management}

Throughout the experiment animals were fed ad-libitum with hay and water and supplemented with concentrates and mineral licks. All protocols and procedures of animal management were according to the guideline set by the animal research and ethics review committee of the College of Veterinary Medicine and Agriculture of Addis Ababa University.

\section{Parasitological examination}

Parasite counts were made at the end of the experiment at three different sites (two shoulder areas and back). Ten by ten centimeter square area was examined at each site on each animal in both groups.

\section{Hematological analysis}

For hematological analysis about $4 \mathrm{ml}$ of blood sample was collected weekly during the study period from jugular vein of all the experimental animals using ethylene diamine tetra acetic acid (EDTA) coated vacutainer tubes (Annex 3). Hematological parameters measured include PCV determination, total RBCs count and total and differential WBCs count. PCV was measured by hematocrit centrifugation technique using a Hawksley microhaematocrit reader [18]. Total RBC and WBC counts were carried out manually using the improved Hemocytometer. A stained thin smear was examined in order to determine the percentage of each type of leukocyte present according to their staining reactions, shape of the nucleus, and presence or absence of granules in their cytoplasm [19].

\section{Data management and analysis}

The entire data collected from the experiment was entered to Excel spread sheet for analysis. Descriptive statistics was used to describe the data. Chi square statistics was used to compare values between infested and non-infested groups. $\mathrm{P}<0.05$ was taken to show statistical difference.

\section{Results}

\section{Parasitological findings}

The Parasite counts made at three different sites (two shoulder areas and back) demonstrated that the mean parasite burden in $10 \mathrm{~cm}^{2}$ area of skin was 16 in infested group whereas the control group did not have any lice.

\section{Packed cell volume (PCV)}

PCV values of both infested and non-infested groups showed gradual decrease compared to their pre-infestation levels. Although mean PCV for the non-infested group appear lower, there was no significant difference $(\mathrm{P}>0.05)$ due to the wide intra group individual variation (Figure 1). Overall mean PCV registered for infested group was $28.78 \pm 1.55 \%$ and for the control group was $27.69 \pm 2.75 \%$. 


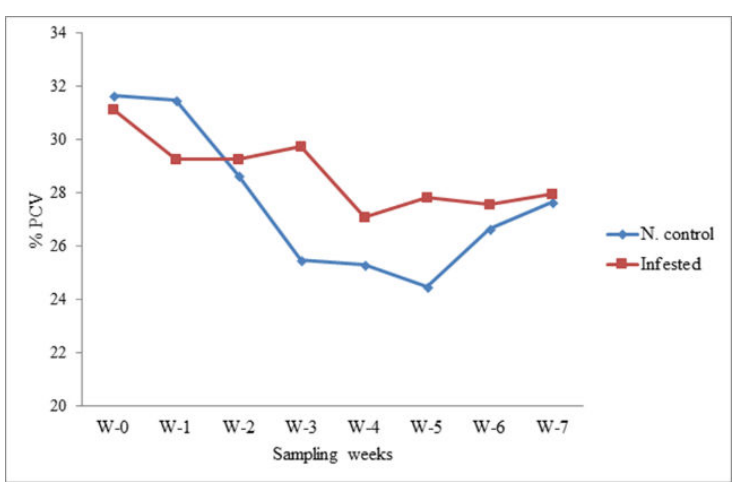

Figure 1: Mean PCV level: There was no significant difference in the PCV value between the two groups.

\section{Total RBC count}

Because of the wide variation in the mean RBC count between the two groups at pre-infestation point, the data was transformed to show the changes in count in relation to $\mathrm{W} 0\left(\mathrm{as}(\mathrm{WxW} 0)^{\star} 100\right.$, where $\mathrm{Wx}$ is the respective week and W0 is week 0 ). The mean decline in total RBC count of infested group was significantly lower than that of the noninfested control (Figure 2). The total RBC count gradually decreased from the day of lice infestation until the end of the experiment. Overall mean RBC count registered for infested group was $10.63 \times 10^{6} \pm 0.94 \times$ $10^{6} / \mu \mathrm{l}$ and for the control group was $11.56 \times 10^{6} \pm 2.09 \times 10^{6} / \mu \mathrm{l}$.

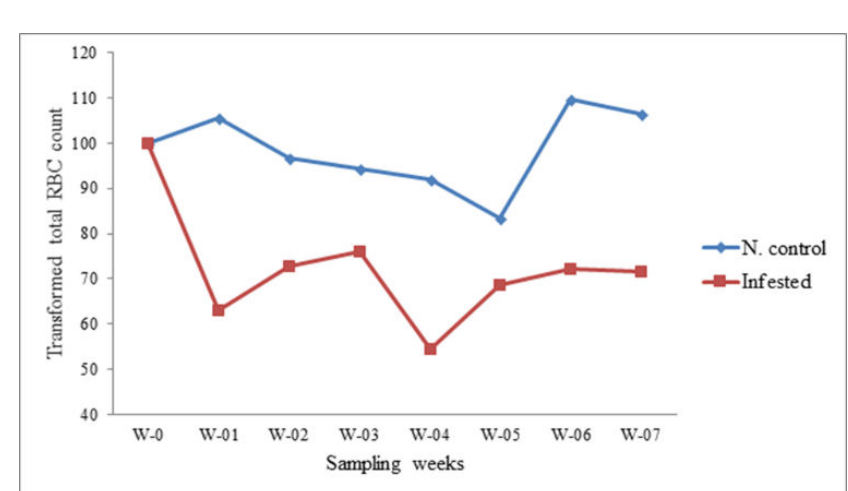

Figure 2: Transformed total RBC count: A significant difference were observed in the number of $\mathrm{RBC}$ between infested and noninfested control group.

\section{Total WBC count}

Because of the wide variation in the mean WBC count between the two groups at pre-infestation point, the data was transformed to show the changes in count in relation to $\mathrm{W} 0\left(\mathrm{as}(\mathrm{WxW} 0)^{\star} 100\right.$, where $\mathrm{Wx}$ is the respective week and W0 is week 0 ). The mean total WBC count of infested group was higher compared to the non-infested control (Figure 3). The total WBC count increased from the day of lice infestation and peak level was registered on week three post infestation whereas non infested control group showed little change in their total WBC. Overall mean WBC count registered for control group was
$11.77 \times 10^{3} \pm 2.49 \times 10^{3} / \mu \mathrm{l}$ and for the infested group was $12.46 \times 10^{3}$ $\pm 1.55 \times 10^{3} / \mu \mathrm{l}$.

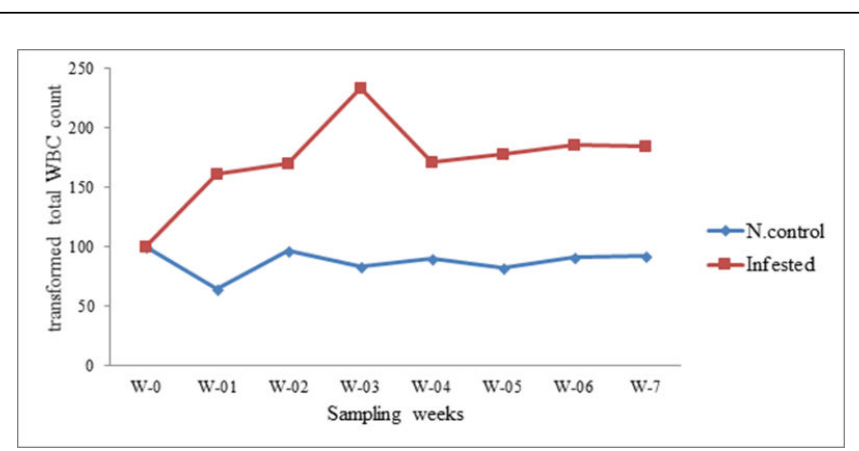

Figure 3: Transformed total WBC count: A significant difference were observed in the number of WBC between infested and noninfested control group.

\section{Differential WBC count}

Lymphocyte percentage had increased on the second week in both groups. While percentages for the control group remained close to preinfection level thereafter, infested group demonstrated a gradual decline until week 6 followed by a rise at the end of the experiment (Figure 4). However, there was no statistically significant difference between the two groups in mean lymphocyte differential count.

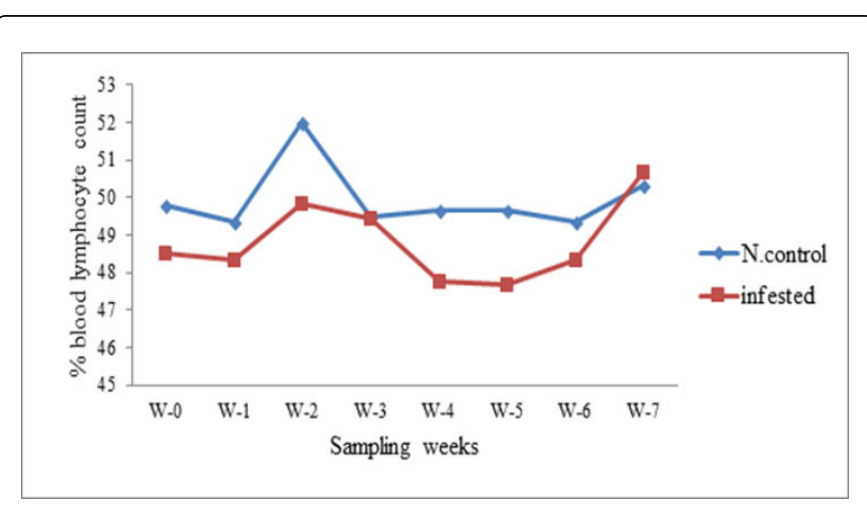

Figure 4: Blood lymphocyte count: There were no significant difference in lymphocyte count between the two groups.

Eosinophil levels were elevated in infested group up to week six and decreased to the last week (Figure 5). The level of eosinophil in infested group was higher than the non infested control group $(\mathrm{P}<0.05)$. 
Page 4 of 5

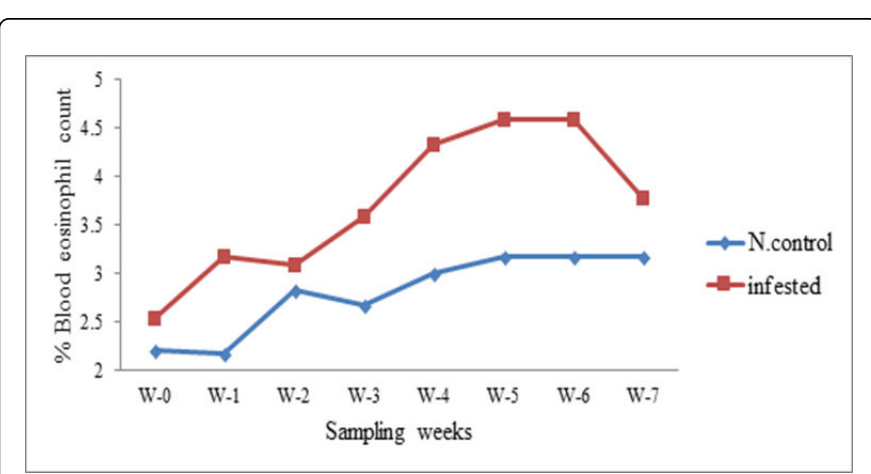

Figure 5: Blood eosinophil count: A significant increase were observed in the number of eosinophil in infested groups compared to non-infested control group.

The non-infested control group demonstrated fluctuating percentages of neutrophil along the experimental period whereas it gradually declined until the end of the experiment in $B$. ovis infested group of sheep. However, there was no statistically significant variation in the levels of neutrophils between the two groups (Figure 6).

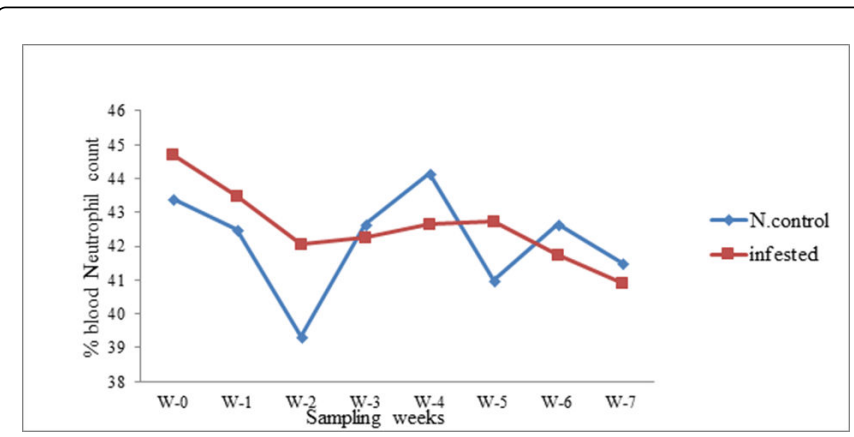

Figure 6: Blood neutrophil count: There was no significant difference in the neutrophil count between the two groups.

Blood monocyte proportion fluctuated along the experimental period in both non-infested and infested groups of sheep (Figure 7). Values did not differ statistically between the two groups $(\mathrm{P}>0.05)$.

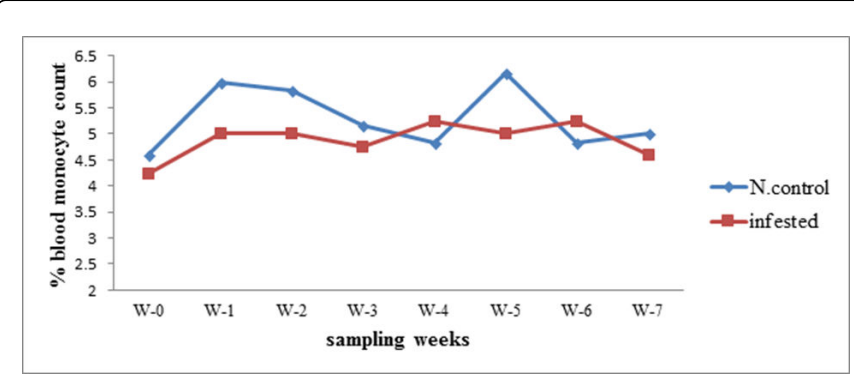

Figure 7: Blood monocyte count: There was no significant difference in the monocyte count between the two groups.

\section{Discussion}

The present study aimed at estimating heamatological changes in sheep infested with high load of $B$. ovis and non-infested control to observe the systemic effect of this parasite on the animals. The absence of significant difference in PCV values between the two groups confirm the fact that the parasite does not feed on blood [7,9]. On the other hand, the simultaneous decline in PCV of both groups may indicate low nutritional profile of the feed provided since there were no internal parasites and blood parasites detected as a possible cause of the fall in PCV. The overall PCV registered for both infested group and control group was within the normal range indicated by Coles [19] suggesting the absence of development of significant anemia.

The overall mean red blood cell count for both infested and noninfested groups was within the normal range indicated in Veterinary Clinical Pathology [19]. However, the infested group had showed lower total RBC count as compared to non-infested control group. This finding is in line with [20] who reported a total decrease in RBC count in sheep infested with mange mite. Anemia in pediculosis may be due to reduction in trace elements like iron as well as increased level of oxidants like Nitric Oxide (NO) and reduced level of antioxidants associated with lice infestation [21]. NO is found to inhibit proliferation of hemopoitic precursors leading to anemia [22,23].

In the present study the mean total WBC count of infested group was higher compared to the non-infested control. This finding is in disagreement with the result of Gurbuz et al. [24] states a significant decrease in the total WBC count in sheep infested with $P$. ovis compared to healthy (control) sheep. This difference might be ascribed to the difference in the parasite studied. Despite such significant difference, the overall mean WBC counts of both groups fall within the normal range described in Veterinary clinical pathology [19].

Differential leukocyte count in this experimental study unequivocally revealed that only eosinophilia characterizes $B$. ovis infestation in sheep while the proportion of other WBC constituents was similar between the two experimental groups. This is in agreement with the finding of Aatish et al. who found significantly increased eosinophil number in sheep infested with mange mite than healthy sheep [20]. An increase in the numbers of circulating eosinophil has frequently been associated with parasitic infestations. This could be due to allergic reactions caused by lice or their products of inflammatory reactions and due to activation of immune system [25].

\section{Conclusions}

The present finding indicates sheep infested with $B$. ovis have caused a decrease in total RBC count and increase in total WBC count and significant eosinophilia compared to non- infested control group. Thus it can be concluded that $B$. ovis infestation results is not only skin damage but also in systemic changes that may significantly alter the physiological and health status of infested animals. Treatment of ectoparasitism especially against $B$. ovis should not undermine the systemic effects of the parasites. Hence, if complete recovery is required all systemic changes should be monitored and corrective measures be taken when necessary (such as against anemia). Further study is required to elucidate the impacts of eosinophils both on the parasite and at the site of infection as it might cause immunopathology. 
Citation: Tadie A, Terefe G, Gizaw Y (2018) Hematological Profile of Sheep Experimentally Infested with Bovicola ovis. J Vet Sci Technol 9: 536. doi:10.4172/2157-7579.1000536

Page 5 of 5

\section{Acknowledgement}

The authors would like to thank Addis Ababa University College of Veterinary Medicine laboratory technicians for passionate encouragement during the research work. This work was supported by the Addis Ababa University Hide and skin thematic research project.

\section{References}

1. Berriatua E, French NP, Broster CE, Morgan KL, Wall R (2001) Effect of infestation with Psoroptes ovis on the nocturnal rubbing and lying behaviour of housed sheep. Appl Anim Behav Sci 71: 43-55.

2. Onu SH, Shiferaw TZ (2013) Prevalence of ectoparasite infestations of cattle in Bench Maji zone, southwest Ethiopia. Vet World 6: 291-294.

3. Dinka AA, Yacob HT, Yalew TA (2008) Part I: Ectoparasite prevalences in sheep and in goats in and around Wolaita soddo, Southern Ethiopia. Revue Méd Vét 159: 450-454.

4. Meseret G, Fikre Z, Gebremedhin R (2014) Identification and prevalence of ectoparasites in cattle and sheep in and around Bishoftu town, central Ethiopia. Anim Vet Sci 2: 124-129.

5. Titchener RN (1983) Prevalence of cattle lice on calves. Vet Record 112: 460.

6. Kettle DS (1995) Medical and Veterinary Entomology. 2nd edn. CAB International, Wallingford, Oxon, UK.

7. Fourie LJ, Horak IG (2000) Status of Dorper sheep as hosts of ectoparasites. Small Rumin Res 36: 159-164.

8. Cotter J, Pearson J (2013) Sheep lice- spread and detection. Farm note Accessed on 24 Apr 2016.

9. Sinclair AN, Britt AG, Cotton CL, Pitman IH (1986) Effects of the sheepchewing louse (Damalinia ovis) on the epidermis of the Australian Merino. Aust J Biol Sci 39: 137-143.

10. Tefera S, Abebe W (2007) A study on ectoparasites of sheep and goats in eastern part of Amhara region, Northeast Ethiopia. J Small Rumin Res 69: 62-67.

11. Seyoum Z, Tadesse T, Addisu A (2015) Ectoparasites Prevalence in Small Ruminants in and around Sekela, Amhara Regional State, Northwest Ethiopia. J Vet Med 2015: 1-6.

12. Khan MA, Schaalje GB (1985) Chlorpyrifos for control of the short nosed cattle louse Haematopinus eurysternus during winter. J Comp Med 49: 361-365.
13. Devaney JA, Craig TM, Rowe LD, Wade C, Miller DK (1992). Effect of low levels of lice and internal nematodes on weight gain and blood parameters in calves in central texas. J Econ Entomol 85: 144-149.

14. Colebrook E, Wall R (2004) Ectoparasite of livestock in Europe and the Mediterranean region. Vet Parasitol 120: 250-274.

15. Dede S, Deger Y, Deger S (2003) Serum profile of calcium phosphor, copper and zinc in healthy and lice infested goats. Indian Vet Brno 71: 341-345.

16. Otter AD, Twomey F, Crawshaw TR, Bates P (2003) Anaemia and mortality in calves infested with the long-nosed sucking louse (Linognathus vituli). Vet Rec 153: 176-179.

17. ADARDO (2007) Ada'a District Agricultural and Rural Development Office.

18. Dagnachew S, Bezie M, Tefrefe G, Abebe G, Barry JD, et al. (2015) Comparative clinico-haematological analysis in young Zebu cattle experimentally infected with Trypanosoma vivax isolates from tsetse infested and non-tsetse infested areas of Northwest Ethiopia. Acta Vet Scand 57: 24.

19. Coles EH (1986) Veterinary clinical pathology. 4th edn. WB Saunders Co., Philadelphia, USA.

20. Aatish HU, Sindhu Z, Iqbal Z, Jabbar A, Tasawar Z (2007) Prevalence of sheep mange in district Dera Ghazi Khan (Pakistan) and associated hematological/biochemical disturbances. Int J Agricult Biol 9: 917-920.

21. Ahmed WM, Habeeb SM, El Moghazy FM, Hanafi EM (2009) Observation on pediculosis in buffalo-cows with emphasis on its impact on ovarian activity and control by herbal remedies. World Appl Sci J 6: 1128-1138.

22. Mabbot N, Sternberg J (1995) Bone marrow nitric oxide production and development of anemia in Trypanosoma brucei infected mice. Infect Immunol 63: 1563-1566.

23. Liew FY, Turner CMR (1999) T cell responses during Trypanosoma brucei infections in mice deficient in inducible nitric oxide synthase. Infect Immunol 67: 3334-3338.

24. Gurbuz G, Semista K (2013) Alterations in Haematological and Biochemical Parameters in Morkaraman Sheep with Natural Psoroptes ovis infestation. Kafkas Univ Vet FakDerg 19: 975-978.

25. Nelson WA, Bell JF, Clifford CM, Keirains JE (1977) Interaction of ectoparasites and their hosts. J Med Entomol 13: 389-428. 